\title{
A Novel Hydrogen Peroxide Sensor Based on Specifically Interacted Silver Dispersed Sol-gel Derived Ceramic Composite Electrode
}

\author{
Dhesingh Ravishankaran, Nobuo Uehara, and Teiji Kato ${ }^{\dagger}$ \\ Satellite Venture Business Laboratory, Utsunomiya University, Yoto 7-1-2, Utsunomiya 321-8585, Japan
}

(Received April 4, 2002; Accepted June 5, 2002)

There is an expanding demand for the fabrication of chemical sensors with highly desired analytical capabilities for the analysis of compounds of biomedical and environmental interest. The selection of the sensing material and the immobilization procedure are crucial for adequate sensors with good compatibility and performance. Recently, sol-gel derived composites have become increasingly used for the design of reproducible and robust sensors. ${ }^{1-4}$ Moreover, the use of bifunctional sol-gel precursors would further enhance the compatibility of the sensors with possible control over the orientation and distribution of the mediator. ${ }^{4-6}$ Such an approach can offer promising prospects in the design of versatile sensing materials. With this idea, a metal dispersed composite electrode was constructed using (3mercaptopropyl)trimethoxysilane (MPS) and silver. MPS is a bi-functional sol-gel precursor containing a silane and a functional thiol group. The thiol group could be used to derive catalytic sites by specific interactions with the desired catalyst, and the silane group could be used for gelation. ${ }^{5-7}$ The advantages of metal catalysis ${ }^{1,2,8,9}$ in combination with the attractive features of sol-gel, such as simple preparation, tunable porosity, low-temperature encapsulation, chemical inertness, and mechanical stability, offer great promise in the fabrication of effective electrodes with the desired characteristics. The newly designed electrode showed promising results for the electrocatalytic reduction of hydrogen peroxide $\left(\mathrm{H}_{2} \mathrm{O}_{2}\right)$ at a reduced overpotential of $-0.05 \mathrm{~V}$ with good sensitivity and stability. Most studies on $\mathrm{H}_{2} \mathrm{O}_{2}$ determination ${ }^{10-13}$ have demonstrated the electrocatalytic oxidation of $\mathrm{H}_{2} \mathrm{O}_{2}$ at relatively higher potentials, which led to possible interference from electroactive substances, such as ascorbic acid and uric acid. However, the remarkably reduced overpotential observed in the present study for the reduction of $\mathrm{H}_{2} \mathrm{O}_{2}$ favors a selective and sensitive determination. In addition, the proposed sensor has the advantages of ease of fabrication, rapid response and remarkable stability.

\section{Experimental}

MPS was purchased from Sigma (USA). $\mathrm{AgNO}_{3}, \mathrm{H}_{2} \mathrm{O}_{2}(30 \%)$ and graphite powder were received from Wako Chemicals, Tokyo, Japan. All other chemicals and reagents used were of analytical grade. Ultrapure water $(\rho=18 \mathrm{M} \Omega)$ was used to

\footnotetext{
† To whom correspondence should be addressed.

E-mail: teiji@cc.utsunomiya-u.ac.jp
}

prepare all of the solutions. A $0.05 \mathrm{M}$ phosphate buffer was used to adjust the $\mathrm{pH}$ of the electrolyte.

Electrochemical experiments were performed with a Potentiostat/Galvanostat HAB 151 connected to a recorder, and a GPIB HA 503G was interfaced with a personal computer (Hokuto Denko Ltd.). A modified composite electrode was used as the working electrode, while $\mathrm{Ag} / \mathrm{AgCl}$ (saturated $\mathrm{KCl}$ ) and a platinum wire were used as reference and counter electrodes, respectively. All measurements were carried out under an atmosphere of high-purity nitrogen.

The modified electrode was fabricated as follows: $2.0 \mathrm{ml}$ of $0.1 \mathrm{M} \mathrm{AgNO}_{3}$ solution was mixed with $1.5 \mathrm{ml}$ of $0.1 \mathrm{M}$ MPS in ethanol and sonicated for nearly $30 \mathrm{~min} ; 2.0 \mathrm{ml}$ of this homogenous gel was well mixed with graphite powder (200 $\mathrm{mg}$ ) for nearly $20 \mathrm{~min}$, and the mixture was allowed for gelation in a desiccator at room temperature for nearly $30 \mathrm{~h}$. The resulting silver dispersed ceramic-graphite composite $(\mathrm{Ag} / \mathrm{CGC})$ was tightly packed into the cavity $(3.0 \mathrm{~mm}$ inner diameter) of a Teflon tube with a stainless-steel base for contact, and dried in air. The surface of the Ag/CGC electrode was polished with smooth polishing paper and rinsed well in ultra-pure water. A bare composite was prepared in a similar fashion without the addition of $\mathrm{AgNO}_{3}$.

\section{Results and Discussion}

When silver nitrate was added to an MPS solution, a curdy-gel mass was obtained due to the complexation of silver with the thiol group of MPS; meanwhile, the silane group initiated gelation by hydrolysis and condensation reactions. Mixing graphite powder with the gel mass resulted in a microporous composite containing dispersed silver. The graphite in the composite ensured the electrical conductivity, the cross-linked silicate network contributed to the rigidity of the composite matrix, and the silver facilitated the electrocatalysis. Figure 1 shows the cyclic voltammograms observed for the reduction of $\mathrm{H}_{2} \mathrm{O}_{2}$ with the $\mathrm{Ag} / \mathrm{CGC}$ and a bare composite electrode in a 0.1 $\mathrm{M} \mathrm{KNO}_{3}$ solution at $\mathrm{pH} 7$ adjusted with a $0.05 \mathrm{M}$ phosphate buffer. The Ag/CGC electrode exhibits a redox peak with anodic and cathodic peak potentials of 0.42 and $0.14 \mathrm{~V}$, corresponding to the silver redox reaction (curve c). However, no characteristic reaction was observed (curve a) in the potential range studied for the bare composite (without silver). The redox reaction of the $\mathrm{Ag} / \mathrm{CGC}$ electrode was stable and reproducible for more than hundred continuous cycles in a 0.1 $\mathrm{M} \mathrm{KNO}_{3}$ solution. Curve b corresponds to the reduction of 8.4 


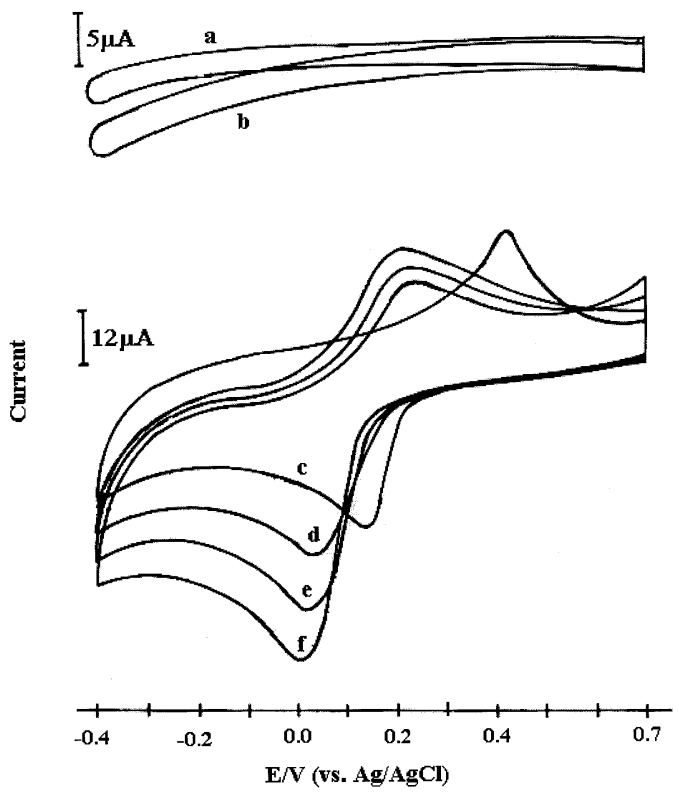

Fig. 1 Cyclic voltammmograms of (a) bare, (b) $8.4 \times 10^{-4} \mathrm{M} \mathrm{H}_{2} \mathrm{O}_{2}$ at bare, (c) Ag/CGC electrode, (d) $5.2 \times 10^{-5} \mathrm{M}$, (e) $2.0 \times 10^{-4} \mathrm{M}$, and (f) $8.4 \times 10^{-4} \mathrm{M} \mathrm{H}_{2} \mathrm{O}_{2}$ at $\mathrm{Ag} / \mathrm{CGC}$ electrode, respectively in a $0.1 \mathrm{M}$ $\mathrm{KNO}_{3}$ solution; $\mathrm{pH} 7$ (0.05 M phosphate buffer); scan rate, $50 \mathrm{mV} / \mathrm{s}$.

$\times 10^{-4} \mathrm{M} \mathrm{H}_{2} \mathrm{O}_{2}$ at the bare electrode. Curves $\mathrm{d}$, e, and $\mathrm{f}$ correspond to the reduction of $5.2 \times 10^{-5} \mathrm{M}, 2.0 \times 10^{-4} \mathrm{M}$, and $8.4 \times 10^{-4} \mathrm{M} \mathrm{H}_{2} \mathrm{O}_{2}$ at the $\mathrm{Ag} / \mathrm{CGC}$ electrode, respectively. As can be seen, the $\mathrm{Ag} / \mathrm{CGC}$ electrode showed an enhanced current response for $\mathrm{H}_{2} \mathrm{O}_{2}$ reduction at a reduced potential of $0.0 \mathrm{~V}$. The presence of silver in the Ag/CGC composite exerted an electrocatalytic effect for the reduction of $\mathrm{H}_{2} \mathrm{O}_{2}$, resulting in a sensitive determination at an extremely reduced potential compared to the bare composite. The current response of the $\mathrm{Ag} / \mathrm{CGC}$ electrode increased with an increase in the concentration of $\mathrm{H}_{2} \mathrm{O}_{2}$, and was proportional to the square root of the potential scan rate in the range from 10 to $200 \mathrm{mV} / \mathrm{s}$, indicating that the catalytic reduction of $\mathrm{H}_{2} \mathrm{O}_{2}$ is a diffusioncontrolled process. Thus, the $\mathrm{H}_{2} \mathrm{O}_{2}$ has to diffuse to the surface of the $\mathrm{Ag} / \mathrm{CGC}$ electrode for the electrocatalytic reduction to takes place. It was observed that in the presence of $\mathrm{H}_{2} \mathrm{O}_{2}$, the reduction peaks were shifted to more negative potentials (curves $\mathrm{d}$, e and $\mathrm{f}$ ), which is possibly due to a matrix effect of the ceramic graphite composite surface for the diffusion of the $\mathrm{H}_{2} \mathrm{O}_{2}$ to reach silver in the composite surface. However, the exact reason is uncertain at present.

It was observed that the loading of silver in the composite has a marked effect on the sensitivity of the $\mathrm{H}_{2} \mathrm{O}_{2}$. The optimum concentrations of the silver, MPS and graphite powders were selected based on the performance of the electrode towards the sensing of $\mathrm{H}_{2} \mathrm{O}_{2}$ with good sensitivity and stability. Figure 2 shows the effect of the $\mathrm{pH}$ on (a) the peak potential and (b) the peak current towards the reduction of $4.0 \times 10^{-5} \mathrm{M} \mathrm{H}_{2} \mathrm{O}_{2}$. It was observed from the figure that the peak potential of the $\mathrm{Ag} / \mathrm{CGC}$ electrode for the reduction of $\mathrm{H}_{2} \mathrm{O}_{2}$ shifted negatively with an increase in the $\mathrm{pH}$ from 2 to 12 (a). The variation of the peak current (b) with the $\mathrm{pH}$ showed a good response to $\mathrm{H}_{2} \mathrm{O}_{2}$ reduction in the $\mathrm{pH}$ range between 4 to 9 . The poor response at higher pHs may be due to possible hydroxylation of the silver in the composite. Thus, a pH of 7 was maintained in amperometric studies, considering the physiological $\mathrm{pH}$ (7.4) condition.
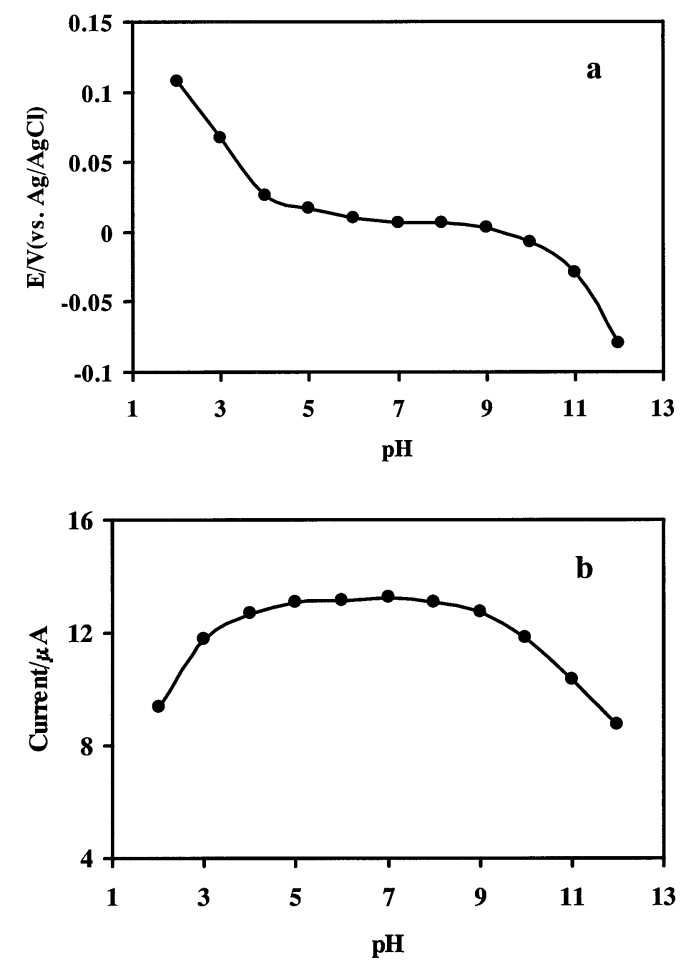

Fig. 2 Effect of the $\mathrm{pH}$ on (a) the peak potential and (b) the peak current for the reduction of $4.0 \times 10^{-5} \mathrm{M} \mathrm{H}_{2} \mathrm{O}_{2}$ at the $\mathrm{Ag} / \mathrm{CGC}$ electrode; scan rate, $50 \mathrm{mV} / \mathrm{s}$.

The hydrodynamic voltammograms (Fig. 3) registered with the $\mathrm{Ag} / \mathrm{CGC}$ electrode in a stirred $0.1 \mathrm{M} \mathrm{KNO}_{3}$ solution containing $5.0 \times 10^{-5} \mathrm{M} \mathrm{H}_{2} \mathrm{O}_{2}$ showed a sigmoidal curve with the maximum response starting from $0.0 \mathrm{~V}$ (curve a). However, with a bare composite electrode, a poor current response was observed (curve b). Thus, a potential of $-0.05 \mathrm{~V}$ was used in an amperometric determination, considering the sensitivity and selectivity. Such a reduced overpotential avoids interference, favoring the selective determination of $\mathrm{H}_{2} \mathrm{O}_{2}$. The addition of equal molar concentrations of commonly interfering species, such as ascorbic acid and uric acid, did not affect the current response for the reduction of $5.0 \times 10^{-4} \mathrm{M} \mathrm{H}_{2} \mathrm{O}_{2}$. The absence of any interference effect was attributed to the low detection potential of the present system.

Figure 4 displays the amperometric response of the modified electrode upon the successive addition of $0.24 \mathrm{mM} \mathrm{H}_{2} \mathrm{O}_{2}$ in 0.1 $\mathrm{M} \mathrm{KNO}_{3}$ at a $\mathrm{pH}$ of 7 . The sensor responds rapidly $(<5 \mathrm{~s})$ to the concentration changes, and increases linearly with the $\mathrm{H}_{2} \mathrm{O}_{2}$ concentration in the range from $9.6 \times 10^{-6}$ to $3.0 \times 10^{-3} \mathrm{M}$ with a correlation coefficient of 0.997 . The detection limit was $6.8 \times$ $10^{-6} \mathrm{M}(S / N=3)$. The relative standard deviation for ten successive determination of $5.0 \times 10^{-5} \mathrm{M} \mathrm{H}_{2} \mathrm{O}_{2}$ was $2.2 \%$. The electrode-to-electrode reproducibility was $3.2 \%(n=8)$. The sensor was stable over a period of two weeks without any significant loss of sensitivity, and $93 \%$ of the response was retained for nearly one month. Moreover, it has the advantage of easy surface renewal by simple mechanical polishing of the used surface. The voltammetric characteristics and the response towards $\mathrm{H}_{2} \mathrm{O}_{2}$ sensing remained constant for repeated polishing, which indicates the remarkable renewal repeatability of the sensor. The excellent stability of the electrode is due to the combined features of the sol-gel composite and a specific interaction of silver with the MPS. The present work is a new advancement in sol-gel sensors; as in most of the sol-gel based 


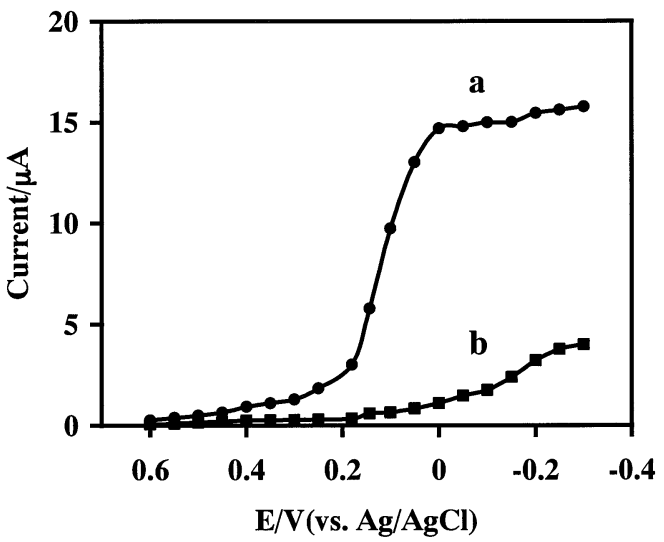

Fig. 3 Hydrodynamic voltammograms for the reduction of $5.0 \times$ $10^{-5} \mathrm{M} \mathrm{H}_{2} \mathrm{O}_{2}$ at (a) an $\mathrm{Ag} / \mathrm{CGC}$ electrode and (b) a bare composite in $0.1 \mathrm{M} \mathrm{KNO}_{3}$; pH 7 (0.05 M phosphate buffer); stirring rate, $300 \mathrm{rpm}$.

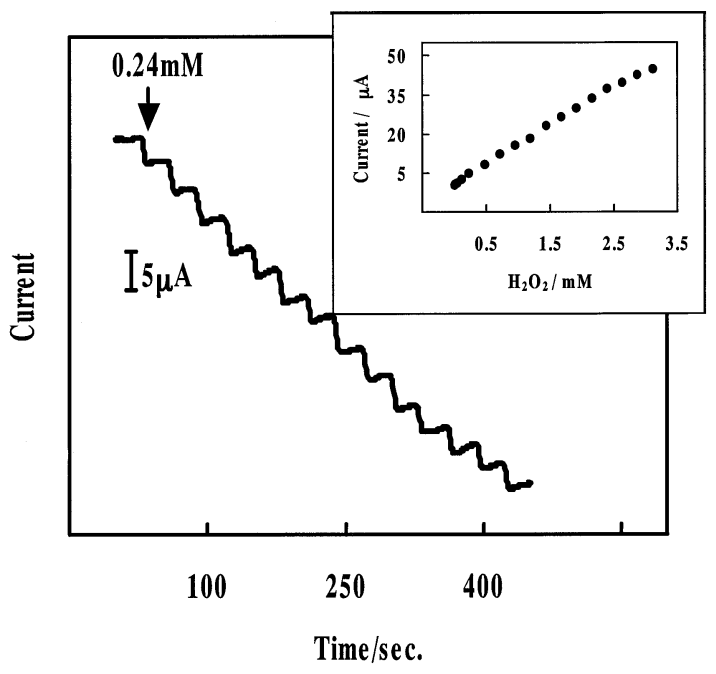

Fig. 4 Current-time response of the Ag/CGC electrode for successive additions of $0.24 \mathrm{mM} \mathrm{H}_{2} \mathrm{O}_{2}$ to a $0.1 \mathrm{M} \mathrm{KNO}_{3}$ solution; other conditions as in Fig. 3. Inset, calibration plot.

sensors, the catalysts are simply immobilized into a silicate network, which leads to a possible leakage of the catalysts in some cases. However, in the present system, stable complex formation between silver and MPS led to a remarkable increase in the stability.

In summary, the silver dispersed sol-gel composite electrode constitutes a simple and attractive approach for the development of promising electrochemical sensors. It has been demonstrated that the MPS provides a good substance for the fabrication of a silver-dispersed composite surface. Furthermore, the favorable combination of a sol-gel composite and silver catalysis provides markedly improved sensitivity, selectivity and reproducibility for $\mathrm{H}_{2} \mathrm{O}_{2}$ monitoring. Based on the present approach, a variety of new sensing materials can be developed by utilizing different active metal ions, such as copper, platinum and iron, in addition to silver. An evaluation of the systems as a biocompatible composite by immobilizing enzymes within the composite is currently under progress in our laboratory. The versatility and the biocompatibility of the ceramic biocomposite and the specific coordination of silver with MPS favor excellent stability and effective immobilization of the enzyme. Since the potential for $\mathrm{H}_{2} \mathrm{O}_{2}$ reduction is considerably reduced, the interference from oxygen may be less. In addition, we can also utilize the system as an enzyme electrode based on the electrocatalytic oxidation of enzymatically liberated $\mathrm{H}_{2} \mathrm{O}_{2}$.

\section{Acknowledgements}

The authors are thankful to Satellite Venture Business Laboratory of Utsunomiya University for financial support.

\section{References}

1. L. Rabinovich and O. Lev, Electroanalysis, 2001, 13, 265.

2. J. Wang, Anal. Chim. Acta, 1999, 399, 21.

3. J. Lin and C. W. Brown, Tr. Anal. Chem., 1997, 16, 200.

4. M. M. Collinson and A. R. Howells, Anal. Chem., 2000, $72,702 \mathrm{~A}$.

5. A. Walcarius, Electroanalysis, 2001, 13, 701.

6. J. Y. Tseng, M. H. Lin, and L. K. Chau, Colloids Surf., 2001, 182, 239

7. G. Che and C. R. Cabrera, J. Electroanal. Chem., 1996, 417,155

8. J. Wang and P. V. A. Pamidi, Anal. Chem., 1997, 69, 4490.

9. M. C. Rodriguez and G. A. Rivas, Anal. Lett., 2000, 33, 2373.

10. K. V. Gobi, K. Tokuda, and T. Ohsaka, J. Electroanal. Chem., 1998, 444, 145.

11. J. Pei and X. Li, Electroanalysis, 1999, 11, 1211.

12. P. Westbroek, E. Temmerman, and P. Kiekens, Anal. Chim. Acta, 1999, 385, 423.

13. R. Garjonyte and A. Malinauskas, Sens. Actuators B, 1999 , 56,93 . 